\title{
Evaluation of biochemical methods performance in clinical laboratories: is this performance suitable for clinical application?
}

\author{
Fereshteh Atabi ${ }^{1}, \underline{\text { Reza Mohammadi }}{ }^{2}$ \\ ${ }^{1}$ Assistant Professor Department of Biochemistry and Biophysics, Faculty of advanced Sciences and technology, \\ Tehran Medical Sciences Islamic Azad University, Tehran, Iran \\ ${ }^{2}$ Assistant Professor Department of Biochemistry, Faculty of Medicine, Tehran Medical Sciences, Islamic Azad \\ University, Tehran, Iran
}

\begin{abstract}
Background: Clinical application of the test results are profoundly influenced by laboratory errors. Nowadays, the best way to evaluate the performance of a method is to determine its sigma scale according to total allowable error (TEa) and analytical errors, including random and systematic errors. In this study, the performance of the measuring kits for biochemical analytes belonging to Pars Azmoon Company, as the most commonly used kits in Iran, was evaluated by determining their deviation index (DI) and sigma scale.

Materials and methods: During the years $2013-17$ and the $15^{\text {th }}$ to $28^{\text {th }}$ runs of the external quality assessment program (EQAP), commercial control materials were sent to about 2000 participating laboratories in each period. Based on the results of measuring the biochemical analytes by these laboratories, method performance of measuring methods was determined according to DI and sigma scale. For determining sigma scale, two different TEa was used.

Results: Based on the TEa introduced by the reference health laboratory of Iran, among the 21 analyzed analytes, DI of the 7,11, and 3 analytes were acceptable (DI up to 2.0) for $100 \%, 90 \%$ and less than $90 \%$ of the reported results, respectively. In sigma scale evaluation of these methods according to TEa of reference health laboratory of Iran and CLIA (Clinical Laboratory Improvement Amendments), 13 and 12 measuring methods were acceptable (sigma of at least 2.0), respectively.

Conclusion: Due to the importance of the test results in medical decision making, it is necessary to improve the performance of measuring methods.

Keywords: Method performance, Biochemical analytes, Deviation index (DI), Sigma scale.

Cited as: Atabi F, Mohammadi R. Evaluation of biochemical methods performance in clinical laboratories: is this performance suitable for clinical application? Medical Science Journal of Islamic Azad University, Tehran Medical Branch 2020; 30(1): 25-32.

Correspondence to: Reza Mohammadi

Tel: +982122006660

E-mail: rmohamadi@iautmu.ac.ir

ORCID ID: 0000-0001-8437-0217

Received: 18 May 2019; Accepted: 2 Jul 2019
\end{abstract}


مجله علوم يزشكى دانشعاه آزاد اسلامى

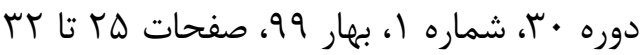

\section{ارزيابى عملكرد روشهاى بيوشيميايى در آزمايشگاههاى بالينى؛ آيا اين عملكرد براى استفاده بالينى مناسب است؟ فرشته عتابى ‘ ، رضا محمدى}

' استاديار، كروه بيوشيمى و بيوفيزيك، دانشكده علوم و فن آورىهاى نوين، علوم بزشكى تهران، دانشكاه آزاد اسلامى، تهران، ايران

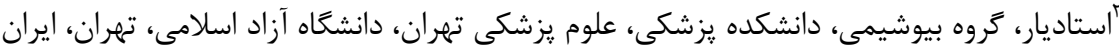

جكيده

سابقه و هدف : كاربرد بالينى نتايج آزمايشها به شدت تحت تأثير خطاهاى آزمايشكاهى قرار دارد. امروزه بهترين راهكار براى تعيين

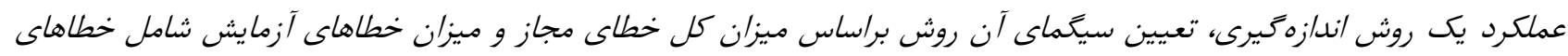

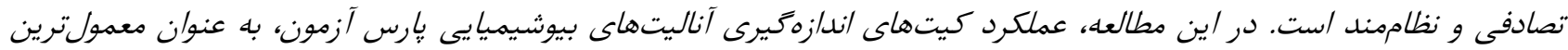

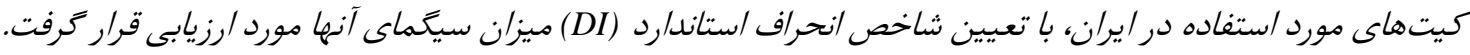

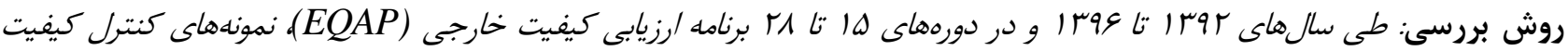

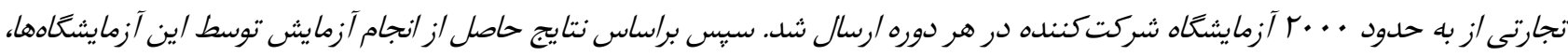

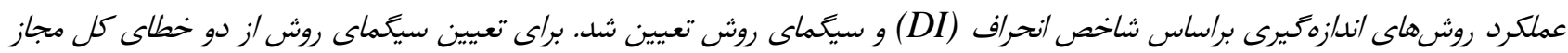

متفاوت/ستفاده شد.

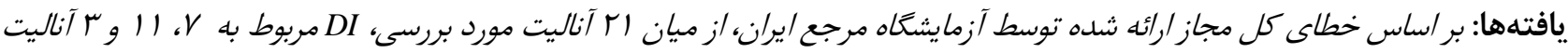

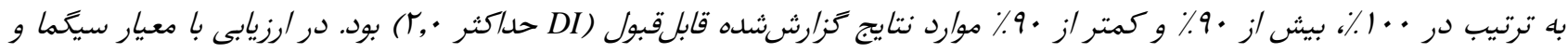

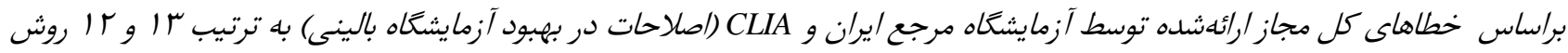

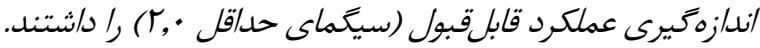

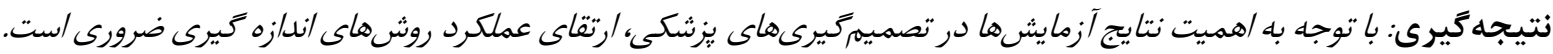

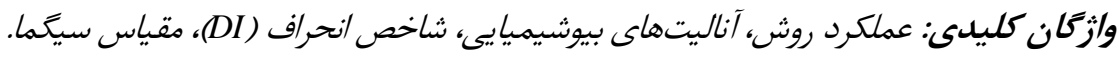

موجود در نمونه هاى بيولوزيكى مختلف، نظير سرم، بِلاسـما، ادرار

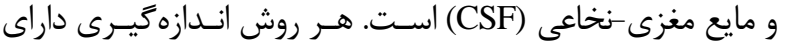

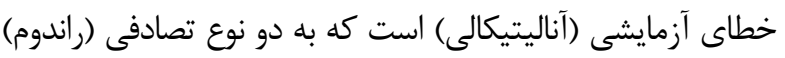

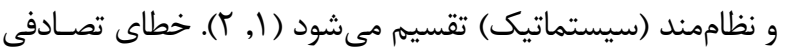

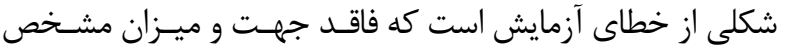

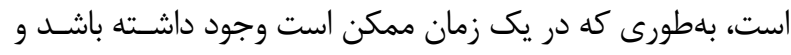

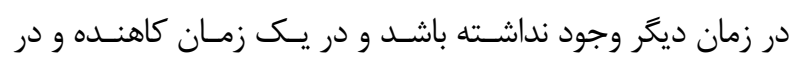

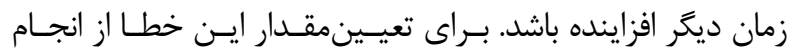

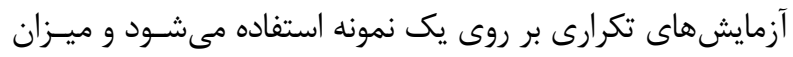

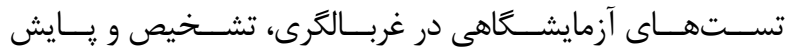

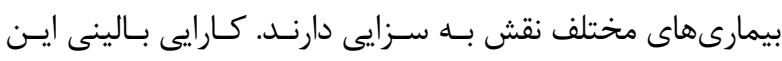

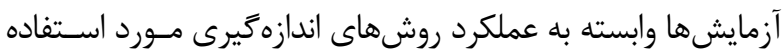

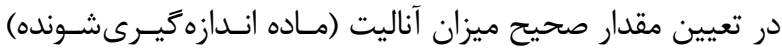

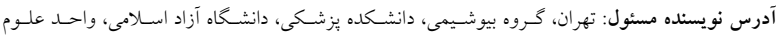

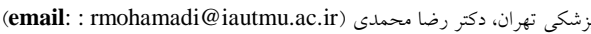
ORCID ID: 0000-0001-8437-0217 تاريخ دريافت مقاله: 9N/T/MN

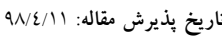


عملكرد يك روش قابل قبول و عـالى تعيسين شـود، در حـالى كـهـ براساس TEa منبع ديكر، اين روش قابلقبول نبوده و رد رد شود.

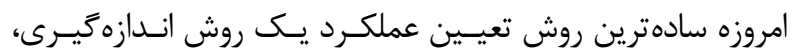

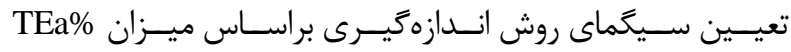

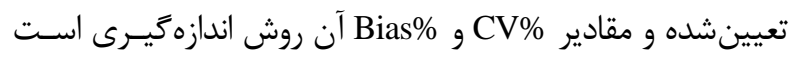

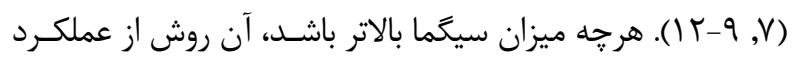

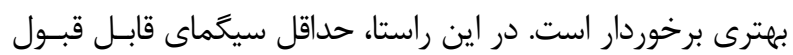

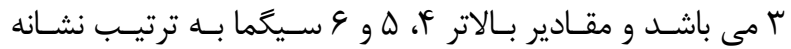

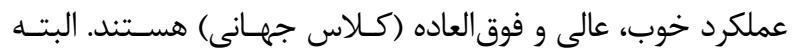

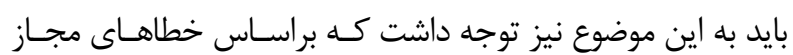
ارائهشده توسط NCEP (برنامه آموزشى ملى كلسترول، در ايسالات

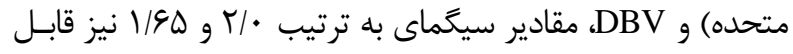

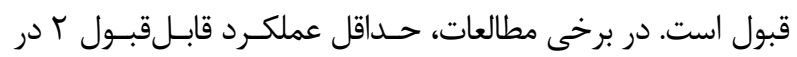
نظر كرفته شده است (بال)

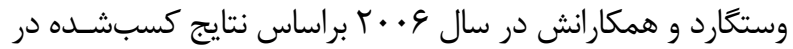

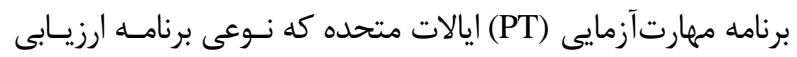

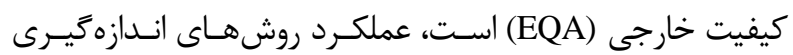

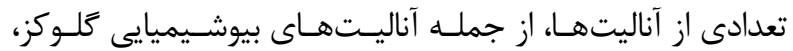

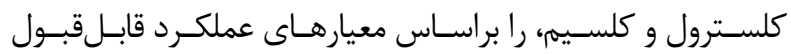

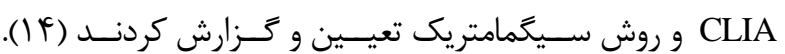

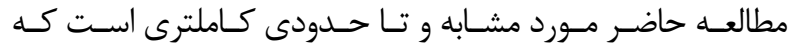
براساس نتايج \& ا دوره برنامه ارزيـابى كيفيـت خـارجى (EQAP)

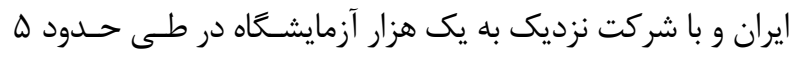

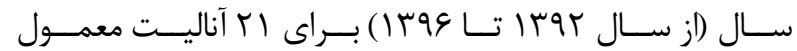
بيوشيميايى صورت كرفته است.

\section{مواد و روشهها ارسال نمونههاى كنترل}

برنامه ارزيابى كيفيـت خـارجى (EQAP) سـالانه بـ بـار در ايـران

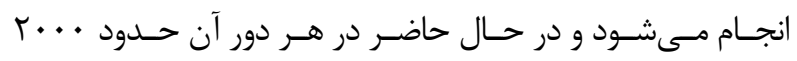

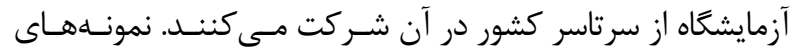

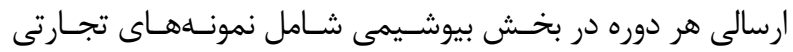

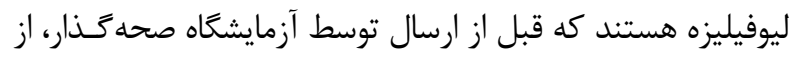
نظر يكنواختى و يايدارى آناليتها صحهكَذارى و تأييد مسىشـوند. براى آزمون يكنواختى الدرصد از ويالهاى كنترل ارسـال شـونده

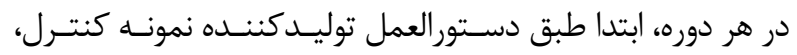

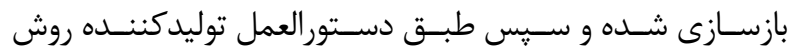
اندازهيرى به صـورت دوتـيى(douplicate) مـورد آزمـايش قـرار

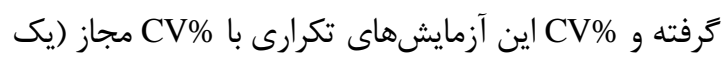

عدمدقت روش الندازمخيرى متناسـب بـا ميـزان يراكنـدكى نتــايج اطراف ميانكين مقادير است كه در بيان آن از انحراف معيـار (SD)

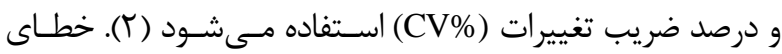

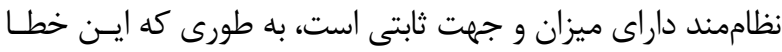
منجر مى شود كه مقادير اندازه كيرىشده مقدار ثابتى بـالاتر و يـاسـا

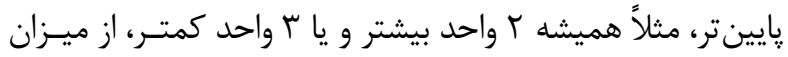

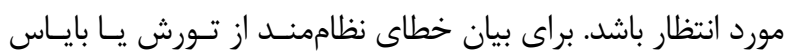

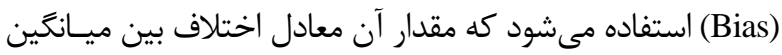

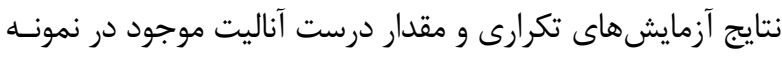

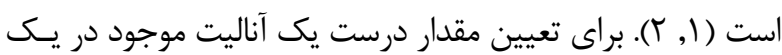

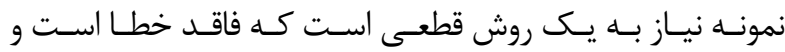

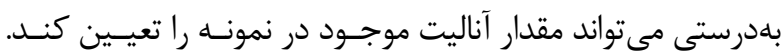

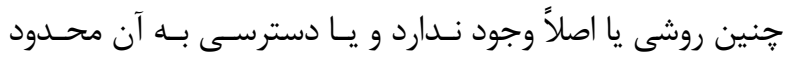
است. به همين دليل در عمـل، تعيـين تـورش واقعسى يـك روش

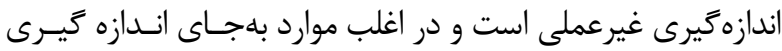

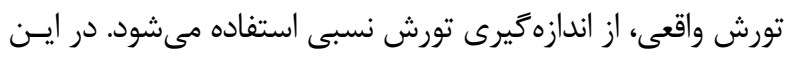

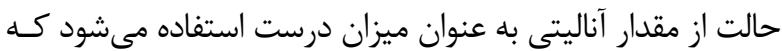

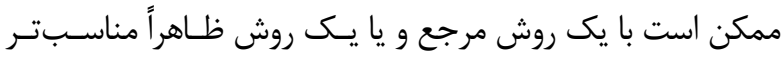

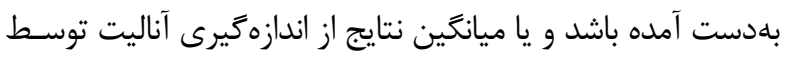

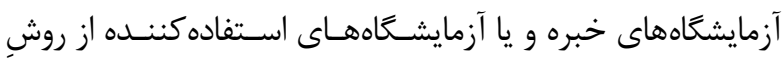

يكسان حاصل شده باشد (Г).

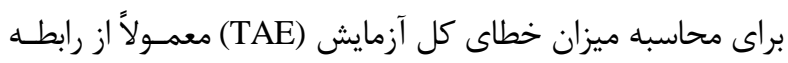

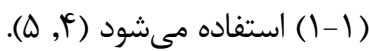

$\mathrm{TAE}=\mathrm{Bias}+2 \mathrm{CV}$

جهت ارزيابى عملكرد يك روش اندازمخيرى، ميـزان خطـاى كـل

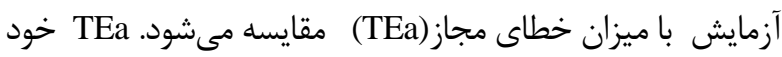
به صورت ميزانى از خطاى آزمايش تعريف مىشود كه در صـورت

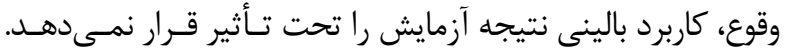

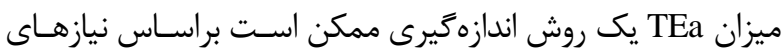

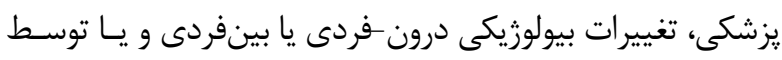
سازمانهاى تنظيم كننده نظيـر CLIA در ايـالات متحـدهد تعيـين

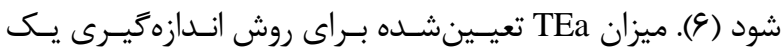

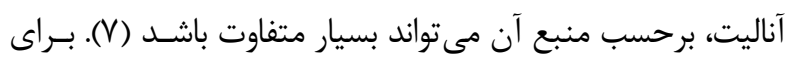

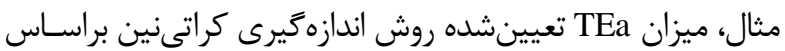
NKDEP (برنامه آموزشى ملى بيمارى كليوى؛ در ايالات متحـدهد)،

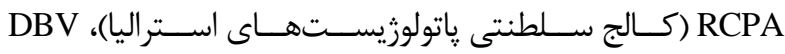

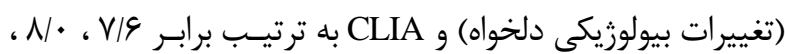

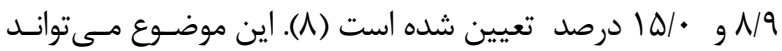

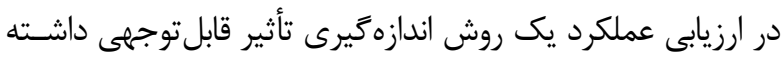

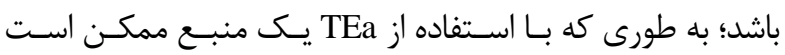


جدول ا. آناليتها به همراه دامنه تعداد اعضاء و ميانگين مقادير هر همكروه

\begin{tabular}{|c|c|c|}
\hline دامنه مقادير ميانخين وزندارشده & دامنه تعداد اعضاء همكروه & 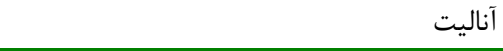 \\
\hline$T / V \Delta-\Delta / ৭ \& \mathrm{~g} / \mathrm{dL}$ & $G M r-\Lambda \Delta r$ & آلبومين \\
\hline$\ \Delta \Lambda-\Delta q \vee U / L$ & $q F \cdot-1 T \Delta q$ & آلكالن فسفاتاز (ALP) \\
\hline$r \cdot|\Lambda-| \Delta \Delta / \mathcal{F} U / L$ & $9 \Delta \cdot-1 T \Delta 9$ & آلانين ترانساميناز (ALT) \\
\hline$q 9-r \Delta \mid \mathrm{U} / \mathrm{L}$ & $r q \Lambda-\Delta q r$ & آميلاز \\
\hline$r \Lambda-r r F U / L$ & $9 \pi r-1 r \Delta \cdot$ & آسيارتات ترانسآميناز (AST) \\
\hline$\cdot / T \Lambda-1 / T \cdot \mathrm{mg} / \mathrm{dL}$ & $19 \cdot-1.90$ & بيلىروبين مستقيم \\
\hline $\mathrm{f} / 9 \mathrm{~V}-1 / \cdot \mathrm{r} \mathrm{mg} / \mathrm{dL}$ & $11 r-11 \cdot 1$ & بيلى روبين تام \\
\hline $9 / \Gamma-I r / V \mathrm{mg} / \mathrm{dL}$ & $999-911$ & كلسيم (Ca) \\
\hline $1 \cdot r-r \Delta F \mathrm{mg} / \mathrm{dL}$ & $\Lambda V \cdot-1 r \cdot q$ & كلسترول \\
\hline$q r-q V \cdot U / L$ & $9 q r-q r V$ & كراتين كيناز (CK) \\
\hline $1 / \cdot-\Delta / \Gamma \mathrm{mg} / \mathrm{dL}$ & $1 \Lambda q-1 r r q$ & كراتىنين \\
\hline$r r-1 r \wedge \mathrm{U} / \mathrm{L}$ & $1 r q-r r r$ & Fاما كلوتاميل ترانسفراز (GGT) \\
\hline$V \Lambda-r V \& \mathrm{mg} / \mathrm{dL}$ & $\wedge 91-1 K \Delta r$ & 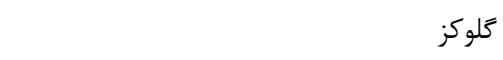 \\
\hline$r \Delta-\varepsilon V \mathrm{mg} / \mathrm{dL}$ & $\Delta G Y-V V r$ & كلسترول-لييويروتئين با جًِالى بالا (HDL-C) \\
\hline GI - rIV $\mu \mathrm{g} / \mathrm{dL}$ & $V \& \Delta-1 . q r$ & آهن (Fe) \\
\hline$r \Delta \varepsilon-V I \varepsilon \mathrm{U} / \mathrm{L}$ & $999-119$ & لاكتات دهيدروزناز (LDH) \\
\hline$r / \mathcal{F}-\Lambda / \Lambda \mathrm{mg} / \mathrm{dL}$ & $V T r-1 . .9$ & فسفر \\
\hline $\mathrm{f} / \mathrm{r}-9 / 9 \mathrm{~g} / \mathrm{dL}$ & $\Delta r q-V 1 q$ & يروتئين \\
\hline q. - rV^ mg/dL & $\Lambda \varepsilon r-1 r \cdot \Lambda$ & ترى تليسريد \\
\hline$\wedge १|-| r \vee \Delta \mathrm{mg} / \mathrm{dL}$ & $\wedge 91-1 Y \vee \Delta$ & اوره \\
\hline $\mathrm{f} / \mathrm{V}-11 / \mathrm{F} \mathrm{mg} / \mathrm{dL}$ & $\wedge r \Delta-11 v$. & اسيد اوريك \\
\hline
\end{tabular}

\section{آناليز نتايج كزارششده آزمايشكاهها}

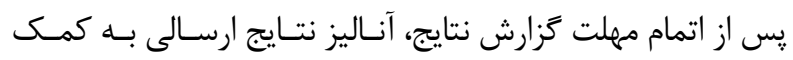

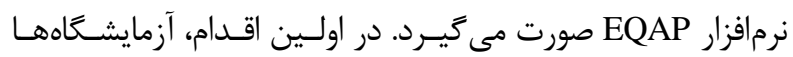
براساس كيـت مـورد اسـتفاده بـه همخـروههـايى (Peer groups)

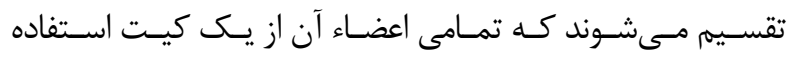

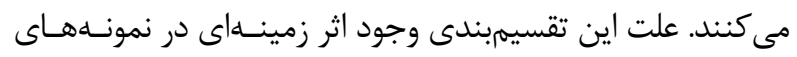
كنترل تجارتى است كه سبب مىشود نتيجه برحسب كيت مـورد

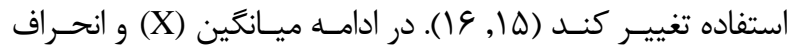

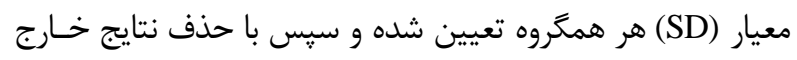

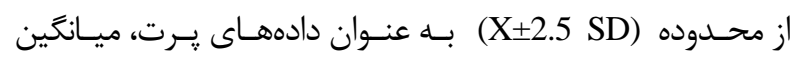
وزندارشده (weighted mean) به عنوان ميزان هدف مورد انتظـار

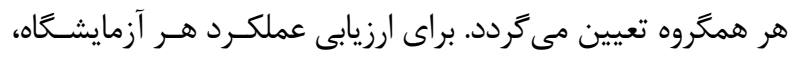

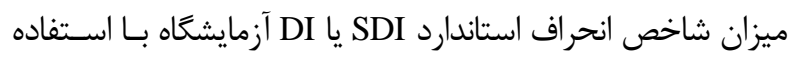
از رابطه (Y-I ) محاسبه مىشود (IV):

$$
\mathrm{DI}=\frac{\text { Lab result }- \text { Weighted mean }}{\mathrm{SD}_{\mathrm{Adj}}}
$$

جهارم خطاى كل مجاز تعيـينشـــه در هـر روش انـدازه كَيــىى)

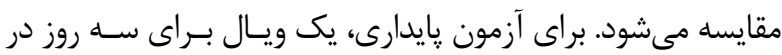

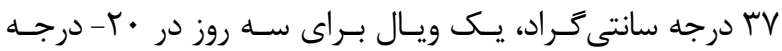

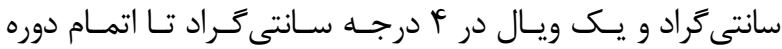

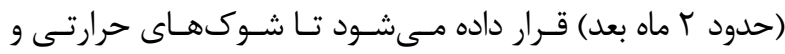

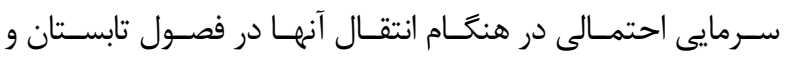

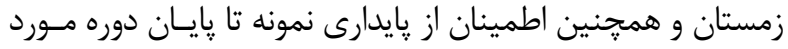

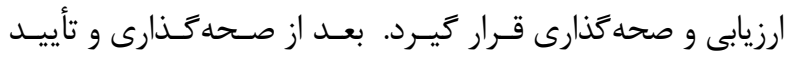

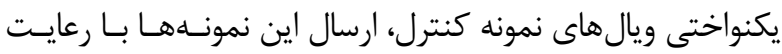

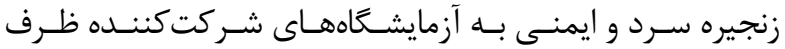
حداكثر r هفته انجام مى شود. آنجام آزمايش و كَزارش نتايج

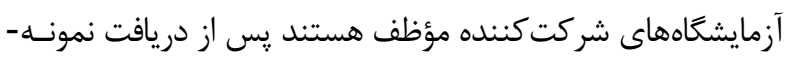

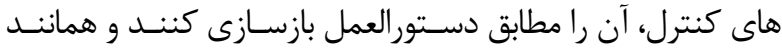

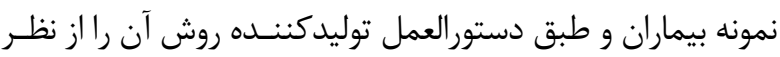

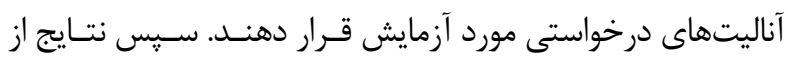
طريق وبسايت EQAP در زمان تعيينشده گزارش مىشوند. 
Sigma $=\frac{\mathrm{TEa} \%-\operatorname{Bias} \%}{\mathrm{CV} \%}$

به دليل نامشخصبودن ميزان تورش، همانند مطالعـهـ انجـامشـده

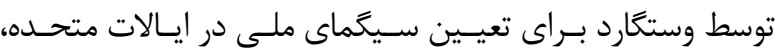
ميزان تورش صفر در نظر گرفته شده و بــه همــين دليـل فرمـول

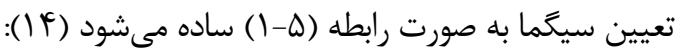
Sigma $=\frac{\mathrm{TEa} \%}{\mathrm{CV} \%}$

در ايسن مطالعـه بـراى تعيـين TEa\% از ميـزان دو برابـر CCV\%

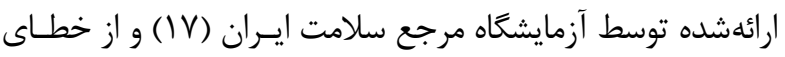
كل مجاز ييشنهادى (N) CLIA) براى مقايسه با معيارهاى موجـود در ايالات متحده استفاده شد.

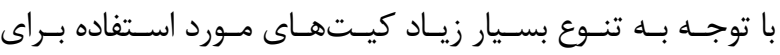
اندازهزيرى كيتهاى بيوشـيميايى در ايــران كـهـ براسـاس نتـايج EQAP

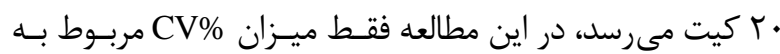

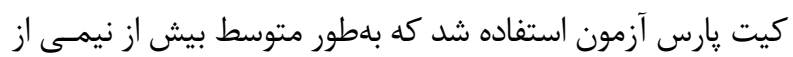

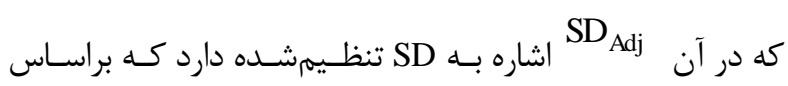
ضريب تغييرات انتخابشده (CCV) ارائهشـده توسـط آزمايشـعاه مرجع سلامت ايران، ميانخين وزندارشده همگروه و رابطــه (r-1) محاسبه مىشود (IV) :

$$
\mathrm{SD}_{\mathrm{Adj}}=\frac{\mathrm{CCV}^{\prime} \quad \text { Weighted mean }}{100}
$$

براساس ميزان DI عملكرد آزمايشگاهها به سه دسته خوب DI تـا

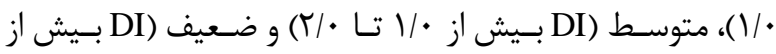

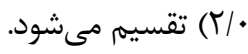

\section{تعيين سيگماى روش}

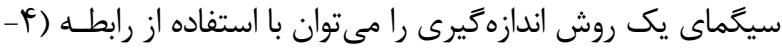

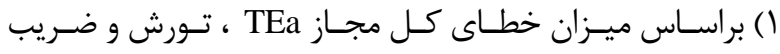

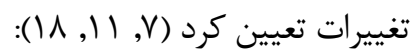

جدول r. عملكرد آزمايشعاههاى شركت كننده براساس ميزان شاخص انحراف استاندارد (DI) و ضريب تغييرات انتخابشده (CCV\%)

\begin{tabular}{|c|c|c|c|c|c|}
\hline \multicolumn{3}{|c|}{ عملكرد آزمايشكاههاى شركت كننده براساس ميزان DI } & \multirow{2}{*}{$\begin{array}{c}\text { CCV\% ارائهشده } \\
\text { ميزان }\end{array}$} & \multirow[t]{2}{*}{ ميانكين CV\% همخروه } & \multirow[b]{2}{*}{ 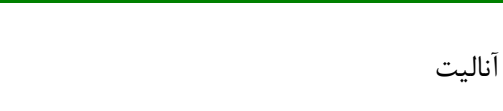 } \\
\hline ضعيف (درصد) & متوسط (درصد) & 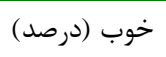 & & & \\
\hline $1 / 0$ & $r 1 / 9$ & $\vee \& / 9$ & $V / Q$ & $9 / 4$ & آلبومين \\
\hline$\cdot 1$ & $19 / 1$ & $\Lambda \Delta / \Lambda$ & $1 \Delta / \Delta$ & $1 \cdot / 4$ & آلكالن فسفاتاز (ALP) \\
\hline$\cdot / \cdot$ & $\Delta / r$ & $9 F / \Lambda$ & $\mid \mathrm{V} / \cdot$ & $\Lambda / T$ & آلانين ترانساميناز (ALT) \\
\hline$\cdot / \Lambda$ & $\mid V / r$ & $\Lambda T / 1$ & $11 / 0$ & $9 / r$ & 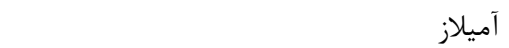 \\
\hline$\cdot 1 \cdot$ & r & $\wedge \varepsilon / \vee$ & $1 Y / \Delta$ & $\Lambda / \cdot$ & آسيارتات ترانسآميناز (AST) \\
\hline$V / T^{c}$ & rr/g & $9 \Lambda / 9$ & $19 / \pi$ & r)/9 & بيلىروبين مستقيم \\
\hline $1 / 9$ & $r \cdot 19$ & $\checkmark V / \Lambda$ & $19 / \pi$ & 1919 & بيلى روبين تام \\
\hline $1 \pi / 9$ & $r \cdot / 1$ & $\Delta V / T$ & $\varphi$, & $\Delta / \Delta$ & كلسيم (Ca) \\
\hline. & $|r /|$ & $\wedge \vee / 9$ & $\mathrm{~V} / \mathrm{G}$ & $4 / 9$ & كلسترول \\
\hline. & $V / q$ & $9 r / 1$ & $1 / 10$ & $9 / 9$ & 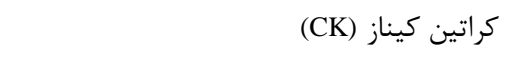 \\
\hline $9 / 1$ & $r q / V$ & $\varepsilon r / \Delta$ & $\Lambda / 9$ & $1 \cdot / r$ & كراتىنين \\
\hline$\cdot 1$ & $1 \cdot 11$ & $\wedge 9 / 9$ & $1 \Delta / V$ & $9 / 1$ & كاما-گلوتاميل ترانسفراز (GGT) \\
\hline$\cdot /$ & $11 / 1$ & $\wedge \Lambda / 9$ & $V / V$ & $F / V$ & 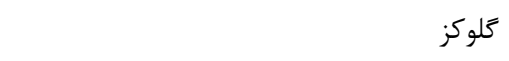 \\
\hline $8 / 9$ & $r V / l$ & $99 / 0$ & $\mid r / \cdot$ & $\mid r / 1$ & كلسترول لييويروتئين با جحالى بالا (HDL-C) \\
\hline$\cdot / V$ & $\mid \Delta / 1$ & $\Lambda F / \mu$ & $\mid Q / \cdot$ & $1 \cdot 19$ & آهن (Fe) \\
\hline$\Delta / \vee$ & $r \& / 1$ & $9 \Lambda / 4$ & $\Lambda / \cdot$ & $\Lambda / \vee$ & ل اكتات دهيدروزناز (LDH) \\
\hline $9 / \Delta$ & TN/D & $9 \mathrm{~s} / \cdot$ & $\mathrm{V} / \Lambda$ & $9 / 9$ & فسفر \\
\hline$r \Delta / r$ & $r T / \mathcal{F}$ & FT/F & $r / q$ & $9 / 1$ & يروتئين \\
\hline$r / r$ & rI/9 & $V \& / T$ & $\mathrm{~V} / \mathrm{G}$ & $V / T$ & ترى تليسريد \\
\hline $11 / 9$ & $r \cdot / f$ & $\Delta \mathrm{V} / \Lambda$ & $\Delta / V$ & $\Lambda / \cdot$ & اوره \\
\hline $1 / 9$ & $r y / 1$ & $V V / T$ & $\mathrm{~V} / \mathrm{V}$ & $V / 1$ & اسيد اوريك \\
\hline
\end{tabular}




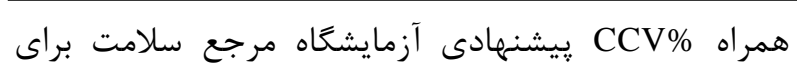

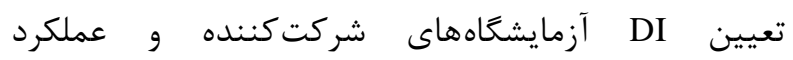

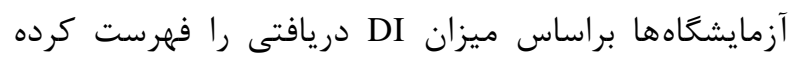
است.

جدول r ميزان سيخماى روش اندازمكيرى پارس آزمون را

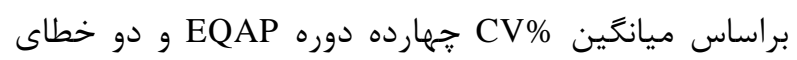

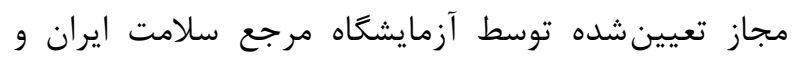

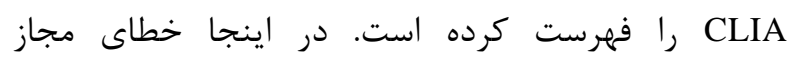

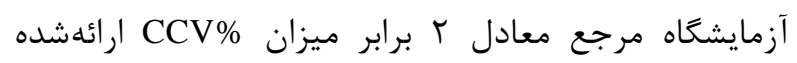

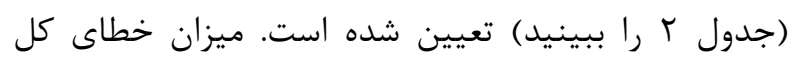

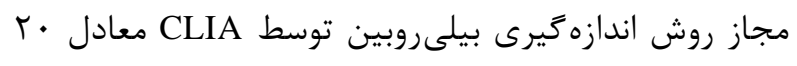
درصد براى مقادير بيشتر از

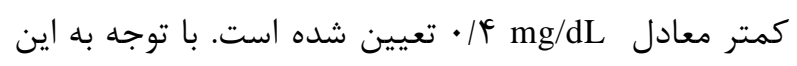

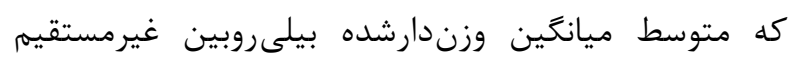
EQAP-15 تا EQAP-28 كل مجاز ييشنهادى TEa در اين مقدار معادل / / 4 مدرصد محاسبه شد.

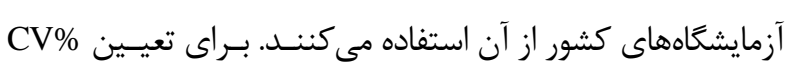

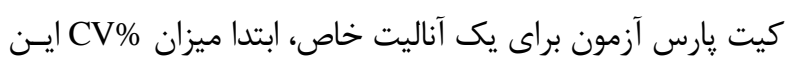

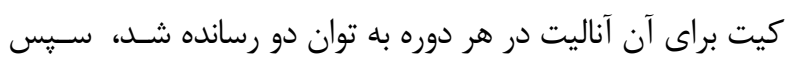

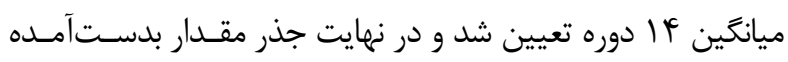

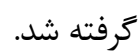

\section{يافته ها}

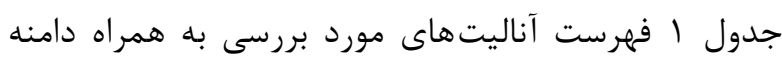

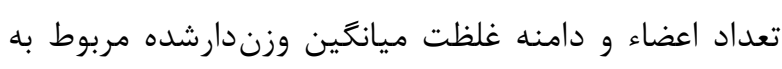

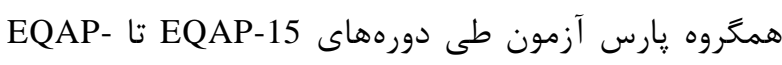

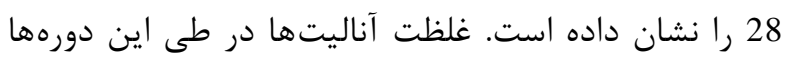

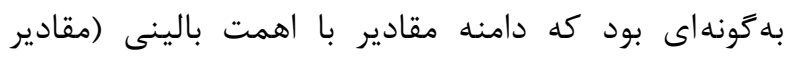

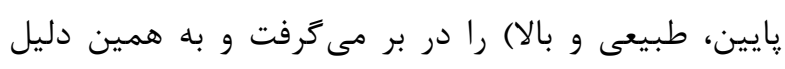

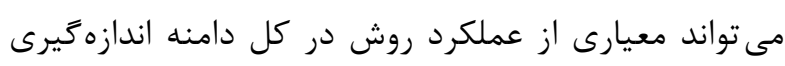

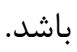
جدول r ميانخين CV\% روش اندازهيرى آناليتهاى

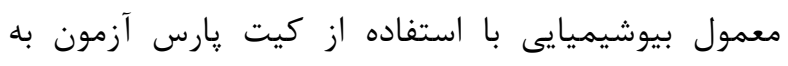

جدول r. عملكرد روش اندازهيرى براساس ميزان سيكما

\begin{tabular}{|c|c|c|c|c|}
\hline & براساس CLIA & & براساس آزمايشخاه مرجي & \\
\hline سيخما & خطاى كل مجاز (درصد) & سيخما & خطاى كل مجاز (درصد) & آناليت \\
\hline $1 / 9$ & $1 . \%$ & $r / r$ & $\mid \phi / \cdot$ & آلبومين \\
\hline$r / 9$ & $r \cdot \%$ & $r / \cdot$ & 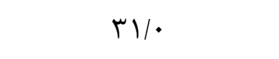 & آلكالن فسفاتاز (ALP) \\
\hline$r / \mathcal{F}$ & $r \cdot \%$ & $r / r$ & $\mu F /$. & آلانين ترانسآميناز (ALT) \\
\hline$r / r$ & $r \cdot / \cdot$ & $r / \Delta$ & $r \mu /$. & آميلاز \\
\hline$r / \Delta$ & $r \cdot \%$ & $r / 1$ & $r \Delta / \cdot$ & آسيارتات ترانسآميناز (AST) \\
\hline$r / V$ & $9 \cdot 11$ & $1 / V$ & $r N / 4$ & بيلىروبين مستقيم \\
\hline $1 / r$ & $r \cdot \%$ & $r / r$ & $r N / F^{e}$ & بيلى روبين تام \\
\hline $1 / V$ & $9 / 4$ & $1 / 4$ & $\Lambda \cdot$ & كلسيم (Ca) \\
\hline$r / \cdot$ & $1 . \%$ & $r / 1$ & $\mid Q / T$ & كلسترول ل \\
\hline$\mu \cdot$ & $r \cdot \%$ & $r / v$ & $r \vee / \cdot$ & كراتين كيناز (CK) \\
\hline $1 / 0$ & $\mid Q / \cdot$ & $1 / V$ & $I V / \Lambda$ & كراتىنين \\
\hline- & ا ارائهنشده & $r / 4$ & $r \mid / 4$ & كاما-خلوتاميل ترانسفراز (GGT) \\
\hline$r / l$ & $1 \cdot \%$ & $r / r$ & $\mid Q / 4$ & 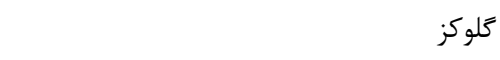 \\
\hline$r / r$ & $r \cdot \%$ & $1 / 1$ & $T F /$. & كلسترول لييويروتئين با حَّالى بالا (HDL-C) \\
\hline $1 / 1$ & $r \cdot \%$ & $T / V$ & $r \cdot \%$ & آهن (Fe) \\
\hline$r / r$ & $r \cdot \%$ & $1 / 4$ & 191. & لاكتات دهيدروزناز (LDH) \\
\hline- & 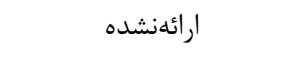 & $1 / 9$ & $\mid \omega / 9$ & فسفر \\
\hline $1 / 1$ & $1 . \%$ & $1 / r$ & $V / \Lambda$ & يروتئين \\
\hline$r / 4$ & $r \Delta / \cdot$ & $r / l$ & $\mid \Delta / r$ & ترى كليسريد \\
\hline $1 / 1$ & १/• & $1 / 4$ & $11 / 4$ & اوره \\
\hline$r / \mathcal{G}$ & $\mid \mathrm{V} / \cdot$ & $r / 4$ & $\mid \omega / 4$ & 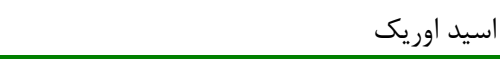 \\
\hline
\end{tabular}


اندازمكيرى يارس آزمون كمتر از ب و و به غير از آلانين ترانسآميناز و كلوكز، حتى كمتر از ك بود.

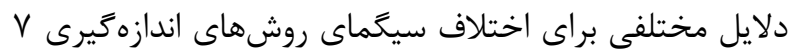
آناليت در مطالعه مطالعه زيوزى كو و مطالعه ما وجود دارد: 1. نتايج مطالعه زيوزى در يك آزمايشكاه بيمارستانى به دست داله

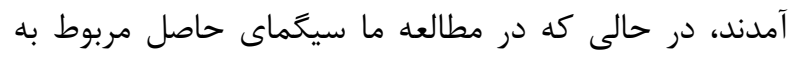

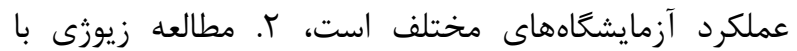

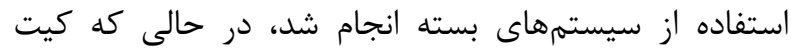
يارس آزمون بر روى سيستمهاى باز و دستكاههاى متنوع

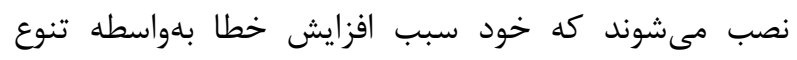

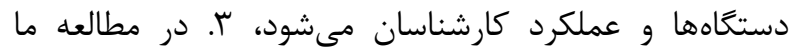
ميزان باياس صفر در نظر گرفته شده است، در حالى در مطالعه زيوزى كو براساس ميزان هدف نمونههاى PT محاسبه

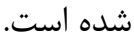

با وجود اين كه به دلايل فوق، شايد مقايسه مطالعه فعلى با

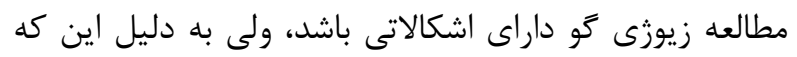
مطالعه مشابه مطالعه ما كمتر انجام شده است و يا نتايج آنها كمتر در دسترس قرار دارد، اين مقايسه تا حدودى مى متواند

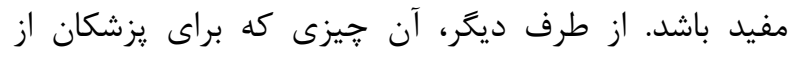

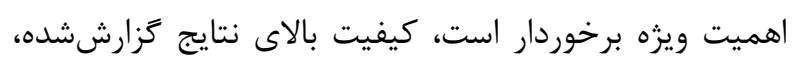
بدون توجه به روش اندازمخيرى و استفاده از سيستههاى

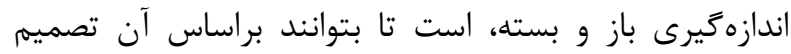
مناسبترى براى بيماران خود بخيرند.

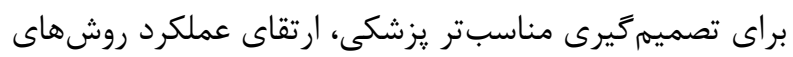

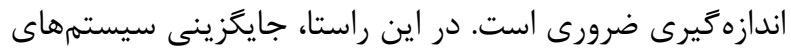

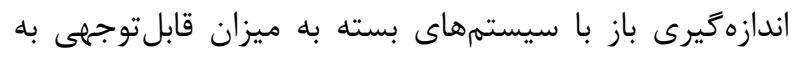

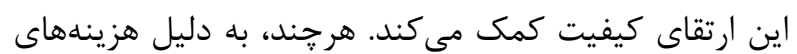
به مراتب بالاتر سيستمهاى بسته، اين جايكزينى مستلزم

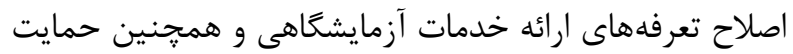

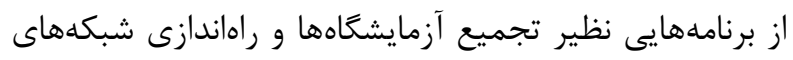
آزمايشكاهى با مديريت يكيارجه است.

\section{تشكر و قدردانى}

اين مطالعه براساس اطلاعات EQAP و با مجوز كتبسى انجمـن

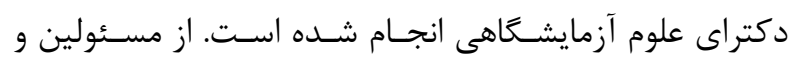

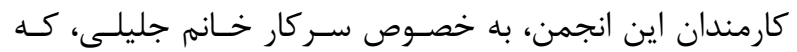
همكارى لازم را داشتند، تشكر و قدردانى مى كنيم.
براى ارزيابى كيفت آزمايشهايى كه در آزمايشكاههاى بالينى

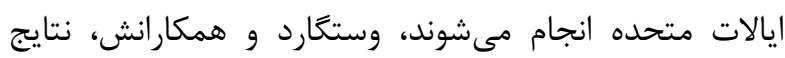

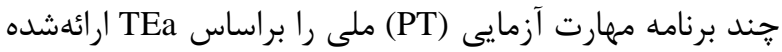
توسط CLIA مورد بررسى قرار دادند. در اين مطالعه آزمايشهاى مختلفى مورد بررسى قرار ترفيتند كه سه آز مايش آن شامل گكلوكز، كلسترول و كلسيم بودند كه در مطالعه ما نيز

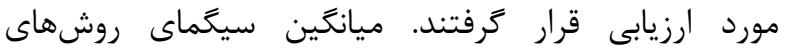

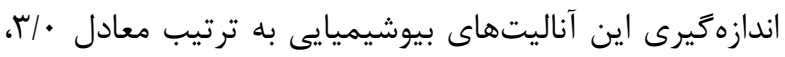

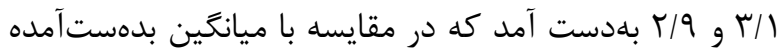

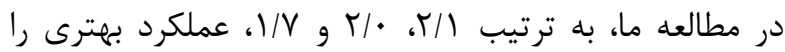
نشان مى دهد.

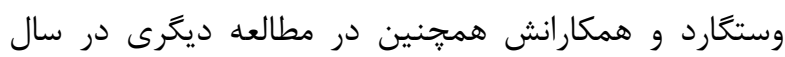

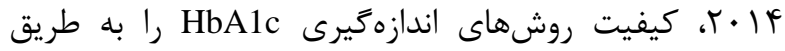

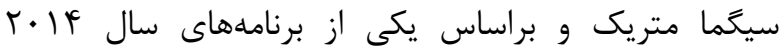

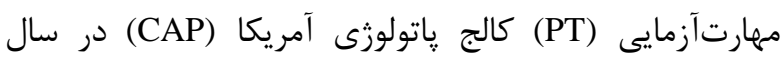

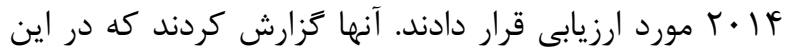
برنامه كه نوعى برنامه ارزيابى كيفيت خارجى است، عملكرد

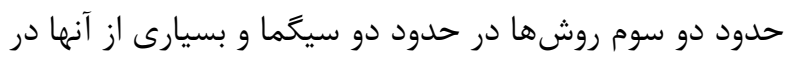

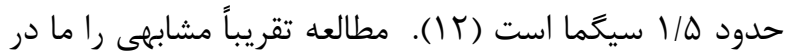

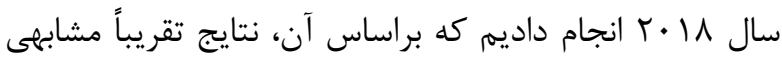

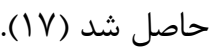

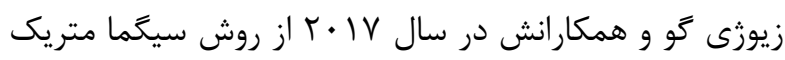

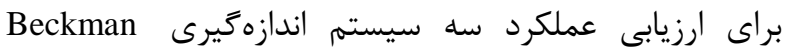

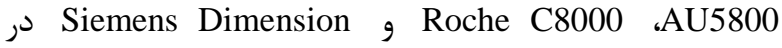
اندازهخيرى ميزان ده آناليت بيوشيميايى معمول، شامل

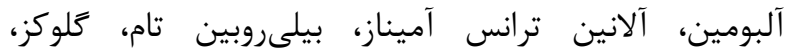
كراتىنين، اوره، يتاسيم، سديم كلر و كلسيم، در جين استفادين

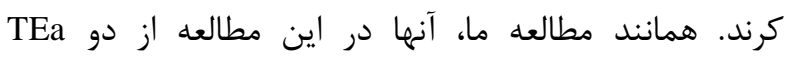
ارائهشده توسط CLIA و يك سازمان داخلى استفاده كردند.

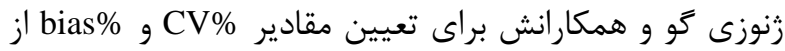

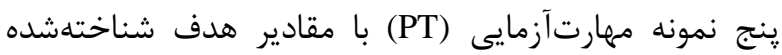

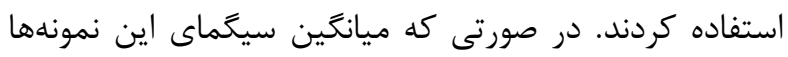
براى هر كدام از اندازمخيرىها تعيين شود، به استثناى ميانكَين سيخماى روش Roche C8000 كه براى اوره معادل

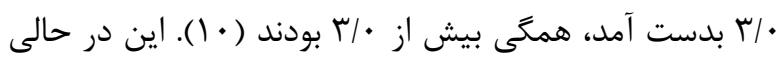

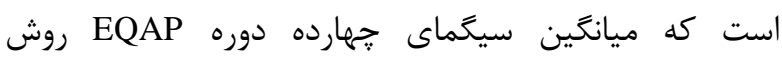

\section{REFERENCES}

1. Biswas S, Bindra M, Jain V, Gokhale P. Evaluation of imprecision, bias and total error of clinical chemistry analysers. Ind J Clin Biochem 2015;30:104-8. 
2. Lumsden J. Laboratory test method validation. Rev Med Veterinaire 2000;151:623-30.

3. Theodorsson E, Magnusson B, Leito I. Bias in clinical chemistry. Bioanalysis 2014;6:2855-75.

4. McGuinness C, Seccombe DW, Frohlich JJ, Ehnholm C, Sundvall J, Steiner G, et al. Laboratory standardization of a large international clinical trial: the DAIS experience. Clin Biochem 2000;33:15-24.

5. Theodorsson E. Quality assurance in clinical chemistry: a touch of statistics and a lot of common sense. J Med Biochem 2016;35:103-12.

6. McPherson RA, Pincus MR, Editors. Henry's clinical diagnosis and management by laboratory methods E-book. New York: Elsevier Health Sciences; 2017.

7. Hens K, Berth M, Armbruster D, Westgard S. Sigma metrics used to assess analytical quality of clinical chemistry assays: importance of the allowable total error (TEa) target. Clin Chem Lab Med 2014;52:973-80.

8. Westgard J. CLIA Requirements for Analytical Quality. Avialable from: https://www.westgard.com/clia.htm. [Accessed at: 2019]

9. Jegede FE, Mbah HA, Aminu M, Yakubu TN, Torpey K. Evaluation of laboratory performance with quality indicators in infectious disease hospital, Kano, Nigeria. Open J Clin Diag 2015;5:1.

10. Guo X, Zhang T, Gao X, Li PTY, Wu Q, Wu J, et al. Sigma metrics for assessing the analytical quality of clinical chemistry assays: a comparison of two approaches. Biochem Med 2018;28:204-14.

11. Chaudhary NG, Patani SS, Sharma H, Maheshwari A, Jadhav PM, Maniar MA. Application of six sigma for the quality assurance in clinical biochemistry laboratory-a retrospective study. Int J Res Med 2013;2:17-20.

12. Westgard JO, Westgard SA. Assessing quality on the Sigma scale from proficiency testing and external quality assessment surveys. Clin Chem Lab Med 2015;53:1531-5.

13. Huysal K, Budak YU. Application of sigma metrics for the assessment of quality assurance using the MQ-2000 PT HbA1c analyzer. Biochem Med 2015;25:416-20.

14. Westgard JO, Westgard SA. An assessment of $\sigma$ metrics for analytic quality using performance data from proficiency testing surveys and the CLIA criteria for acceptable performance. Am J Clin Pathol 2006;125:343-54.

15. Mohammadi R, Norozi V. HbA1c External Quality Assessment: Commutable vs Noncommutable Samples. Biomed Pharmacol J 2016;9:163-8.

16. Miller WG. Specimen materials, target values and commutability for external quality assessment (proficiency testing) schemes. Clin Chim Acta 2003;327:25-37.

17. Sudhakar B, Reddy AS, Fallerio J. Comparison of three methods for measurement of blood HbA1c as to reliability. Int J Bioassays 2014;3:3000-4.

18. Mao X, Shao J, Zhang B, Wang Y. Evaluating analytical quality in clinical biochemistry laboratory using Six Sigma. Biochem Med 2018;28:253-56. 